\title{
The Linear Correlation of Serum Level Thrombospondin-1 with Lipid Profile in Patients with Diabetic Disease Type II
}

\author{
Dr. Wijdan Rajh Hamza Al-Kraity \\ Ph. D. in Medical Physiology, Department Medical Laboratories Techniques, Al-Toosi University College, Iraq \\ *e-mail: dr.wijdan rajh@altoosi.edu.iq
}

\begin{abstract}
The study was conducted on randomly selected 65 type 2 diabetic patients attending the diabetes mellitus center in Al-Sadder Teaching City in Al-Najaf province, Iraq and a group of 24 apparently healthy subjects were included as a control group. The Study was carried out from August 2013 to February 2014.The patients' age was ranging of 35 to 64 years old.The results indicated a significant increase $(p<0.05)$ in serum TSP-1, Cholesterol, TG,VLDL-C, LDL-C levels and a significant decrease $(p>0.05)$ in serum $H D L-C$ level in diabetic patients in comparing with healthy groups. The results have been shown significant positive correlation $(P<0.05)$ TSP-1 and cholesterol, TSP-1 and TG, TSP-1 and LDL-C, TSP-1 and VLDL-C in DM patients. The results have been shown significant negative correlation $(P<0.05)$ between TSP-1 and HDL-C in type 2 diabetic patients.
\end{abstract}

Keywords: Type II diabetic mellitus , Lipid profile and TSP-1

\author{
Article Information \\ Received: November 20, 2020; Online: December 4, 2020
}

\section{INTRODUCTION}

Diabetes mellitus (DM) is a group of metabolic disorders of carbohydrates metabolism, this condition occurs when inadequate uptake of glucose by the cells of the body causes high levels of glucose in the blood (hyperglycemia) (CDA,2008; ,CDA,2013). Patients with type II diabetes mellitus are insulin resistant, have relatively low insulin production, or both, some patients with type II diabetes may eventually require insulin when other medications fail to control blood glucose levels adequately (Leahy and William, 2002). Type II diabetes is most commonly associated with obesity in middle-aged individuals. It is due to reduction in the number or affinity of insulin receptors on the plasma membrane of cells in target tissues, or an abnormal binding of insulin to the receptors (Thabrew and Ayling,2001). The major forms of diabetes are divided into those caused by deficiency of insulin secretion due to pancreatic $\beta$-cell damage (type $1 \mathrm{DM}$ ), and those that are a consequence of insulin resistance occurring at the level of skeletal muscle, liver, and adipose tissue, with various degrees of $\beta$-cell impairment (type 2 DM)( Alemzadeh et al.,2008; CDA, 2013).

Thrombospondin-1 (TSP-1) is a well-studied glycoprotein that have many motifs (i.e., adhesive domains; $N$-terminal domain, procollagen homology, type I repeats, type II, type III repeat , $C$-terminal domain) (Qian and Tuszynski,1996).TSP-1 suppresses endothelial cell proliferation, migration, and tube-formation and induces endothelial apoptosis (Jimenez et al.,2000).Thus, TSP-1 is an endogenous inhibitor of angiogenesis under physiological and pathological conditions, including in the context of malignancy (Adams and Lawler,2004).TSP-1 also modulates the extracellular matrix and leads to degradation and remodeling of connective tissues (Lawler,2000). TSP-1 plays an important role in the regulation of various biological activities, including vascular homeostasis, immunity, and 
wound healing (Bauer et al.,2010; Lopez-Dee et al.,2011).

\section{METHODS}

\section{Collection of blood samples}

Five milliliters of venous blood samples were drown using a disposable needle and plastic syringes from each patients and controls subject. Blood was left at room temperature for 10 minutes to clot, centrifuged $6000 \mathrm{rpm}$ for 10 minutes, and then serum was separated and transported into new disposable tubes.

\section{Biochemical markers}

\section{Lipid profile}

\section{Measurements of total cholesterol (TC)}

Specific kit for measuring human TC concentrations in serum was supplied by Biolabo SA, France.

\section{Measurements of high density lipoprotein (HDL)}

Specific kit for measuring human HDL concentrations in serum was supplied by Biolabo SA, France .

\section{Measurements of triglycerides(TG)}

Specific kit for measuring human TG concentrations in serum was supplied by Biolabo SA, France
Calculation of low density lipoprotein (LDL)

Low density lipoprotein was calculated by this formula: $\mathrm{LDL}(\mathrm{mg} / \mathrm{ml})=\mathrm{TC}(\mathrm{mg} / \mathrm{dl})$ $\operatorname{VLDL}(\mathrm{mg} / \mathrm{dl})-\mathrm{HDL}(\mathrm{mg} / \mathrm{dl})$.

\section{Determination of serum Thrombospondin-1 level}

Thrombospondin ELISA Kit For the quantitative determination of human thrombospondin-1 (TSP-1) concentrations in serum was supplied by CUSABIO, USA.

\section{Statistical Analysis}

The data of present study were articulated as (Mean \pm Standard Error), the statistical analysis (descriptive statistics, Correlation coefficients, $p$ value) were calculated by using megastat and Graphpad prism, when $\mathrm{P}$ value $<0.05$ was statistically a significant

\section{RESULTS \\ Comparison between diabetics mellitus patients and healthy groups}

The results of table (1) indicate a significant increase $(\mathrm{P}<0.05)$ in serum TSP-1, cholesterol,Triglyceride ,VLDL-C , LDL$\mathrm{C}$ levels and a significant decrease $(\mathrm{P}<0.05)$ in serum HDL-C level in diabetic patients in comparing with healthy groups.

Table (1): Serum levels of TSP-1and lipid profile parameters in diabetic mellitus patients and control groups.

\begin{tabular}{|l|c|c|}
\hline \multirow{2}{*}{ Griteria } & \multicolumn{2}{|c|}{ Mean \pm S.E. } \\
\cline { 2 - 3 } & Control & Patients \\
\hline Lipid profile & N=24 & N=40 \\
\hline TSP-1 ng/ml & $1.181 \pm 0.226$ & $10.942 \pm 0.043 *$ \\
\hline Cholesterol mg/dl & $112.54 \pm \mathbf{5 . 2 6}$ & $435.35 \pm 24.12 *$ \\
\hline TG mg/dl & $\mathbf{6 4 . 8 3} \pm \mathbf{7 . 1 3}$ & $497.80 \pm 28.53 *$ \\
\hline VLDL-C mg/dl & $18.33 \pm 2.05$ & $\mathbf{9 9 . 5 5 3} \pm \mathbf{5 . 7 0 6} *$ \\
\hline LDL-C mg/dl & $95.46 \pm 3.74$ & $179.535 \pm 1.335 *$ \\
\hline HDL-C mg/dl & $47.21 \pm \mathbf{0 . 9 0}$ & $\mathbf{2 5 . 0 9 5} \pm \mathbf{0 . 9 9 7} *$ \\
\hline
\end{tabular}

$(*)$ Statistically significant differences $(\mathrm{p}<0.05)$ between patients and control groups. 


\section{Thrombospondin-1 and lipid profile levels}

The results of correlation and linear regression between TSP-1 and lipid profile levels in patients are indicated:

1. The presence of a positive correlation $(\mathrm{P}<0.05)$ between TSP-1 and cholesterol levels of DM patients ( $\mathrm{r}=0.942)$, (figure 1 ).

2. 1-The presence of a positive correlation $(\mathrm{P}<0.05)$ between TSP-1and triglyceride levels of DM patients ( $\mathrm{r}=0.896)$, (figure 2$)$.

3 . The presence of a positive correlation $(\mathrm{P}<0.05)$ between TSP-1 and VLDL levels of DM patients ( $r=0.897)$, (figure 3).

4. The presence of a positive correlation $(\mathrm{P}<0.05)$ between TSP-1and LDL levels of DM patients $(r=0.971$, TSP- $1=-45.863+$ $0.311 \mathrm{LDL}$ ), (figure 4).

5. 1-The presence of a negative correlation $(\mathrm{P}<0.05)$ between TSP-1 and HDL levels of DM patients $(r=-0.977)$, (figure 5$)$.

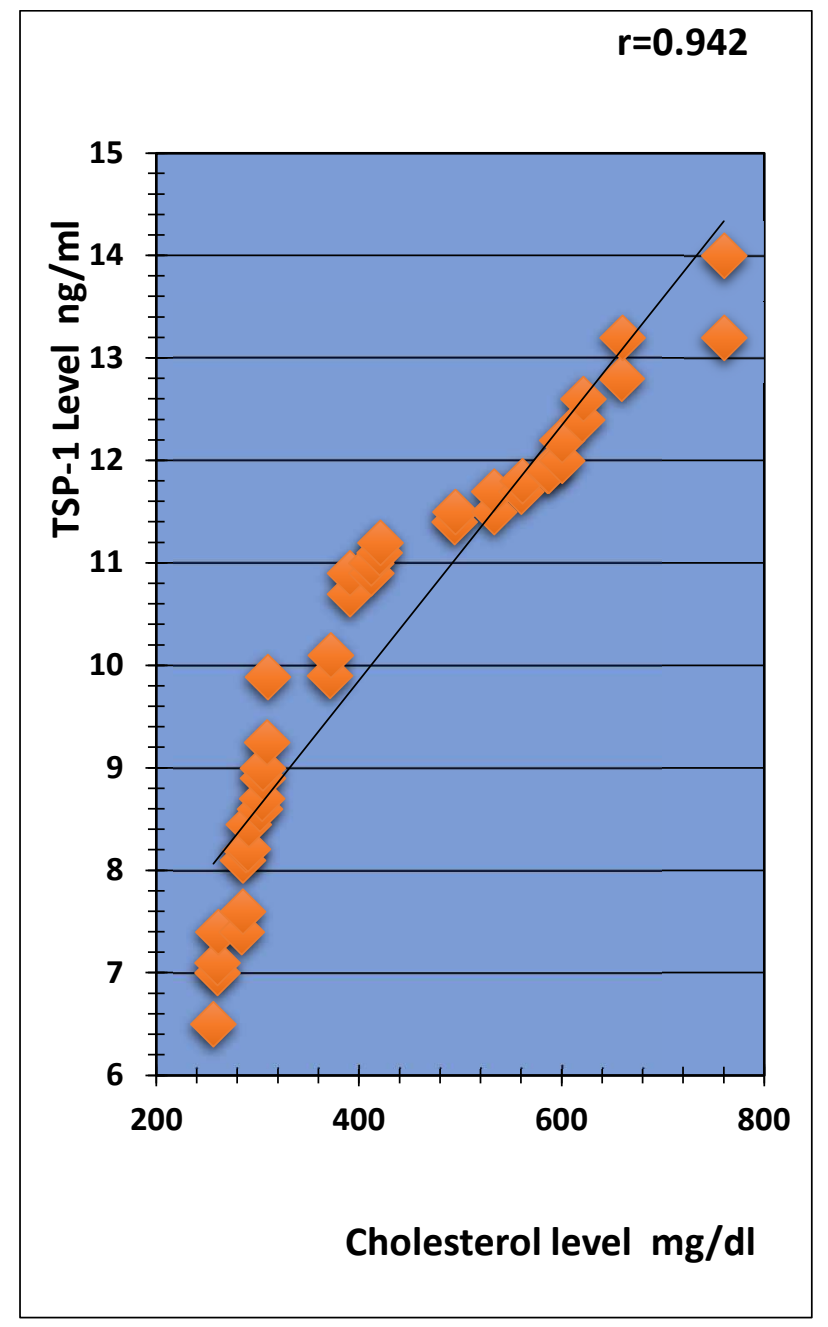

Figure (1): Correlation between TSP-1 and Cholesterol in type $2 \mathrm{DM}$ patients.

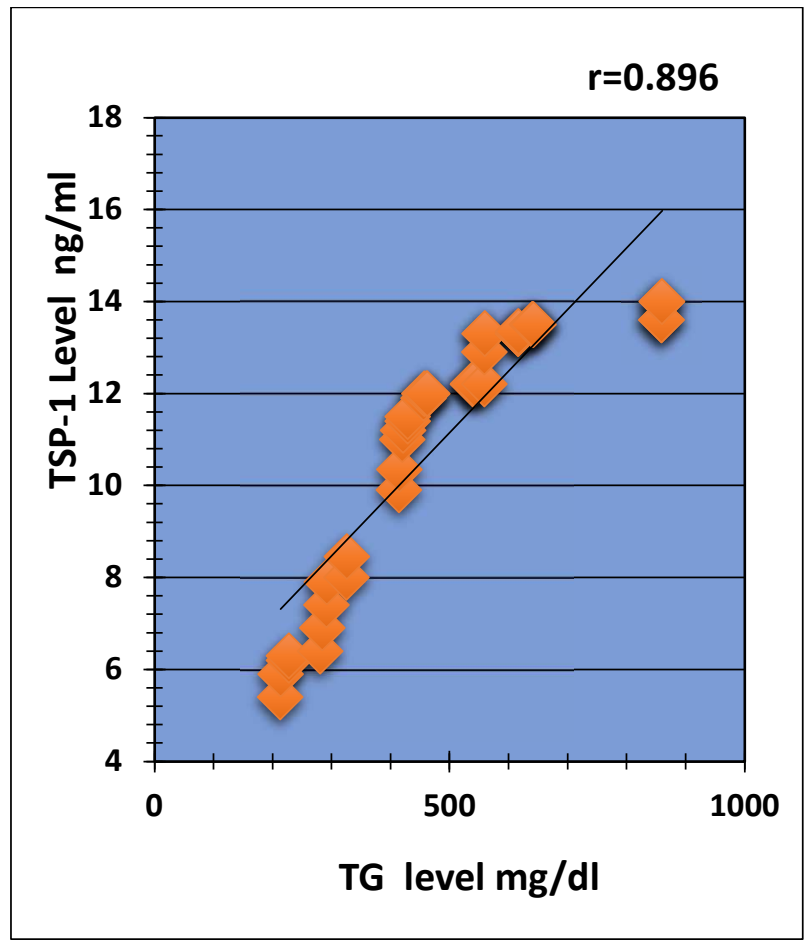

Figure (2): Correlation between TSP-1and triglyceride in type $2 \mathrm{DM}$ patients.

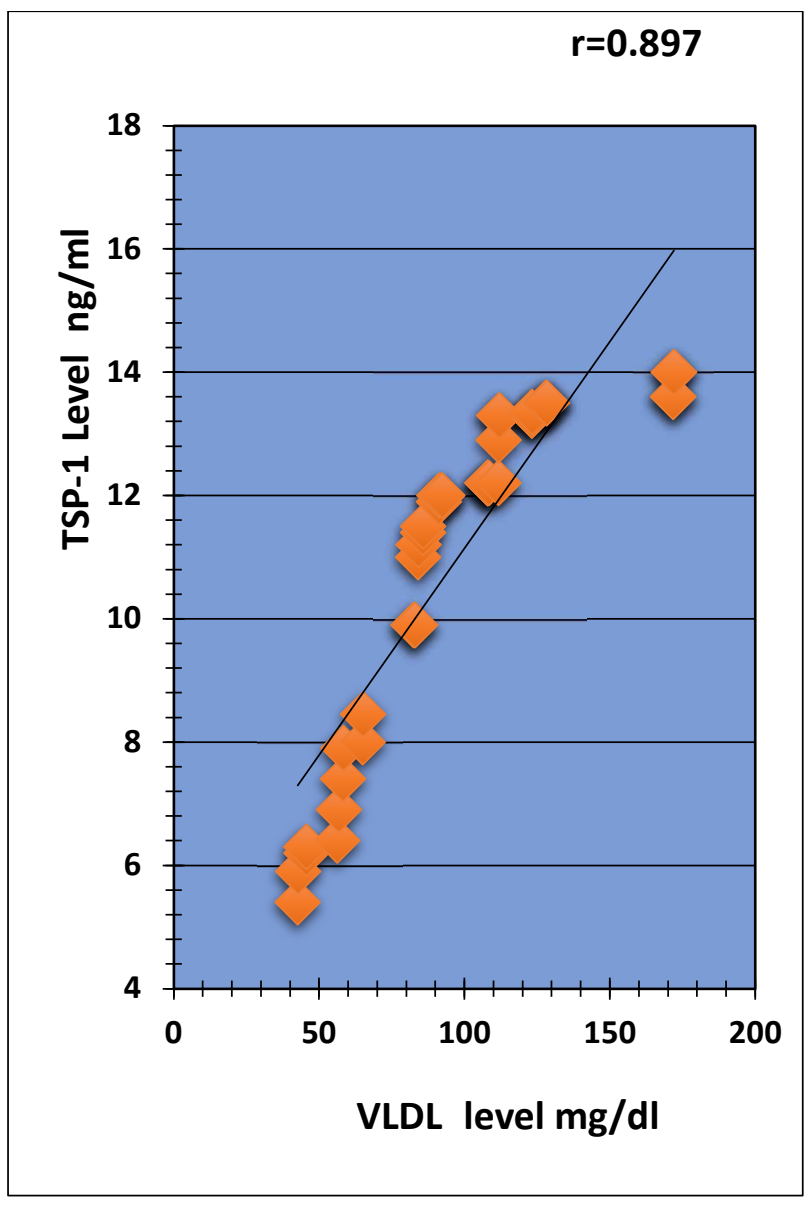

Figure (3): Correlation between TSP-1 and VLDL in type 2 DM patients. 


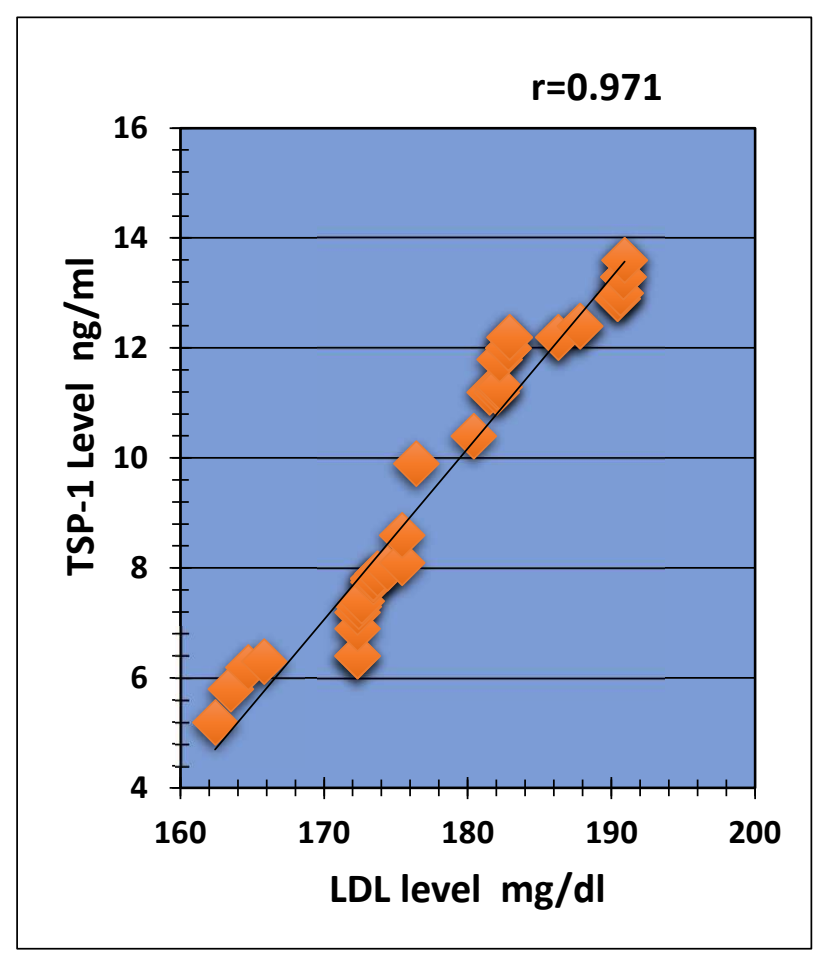

Figure (4): Correlation between TSP-1 and LDL in type 2 DM patients.

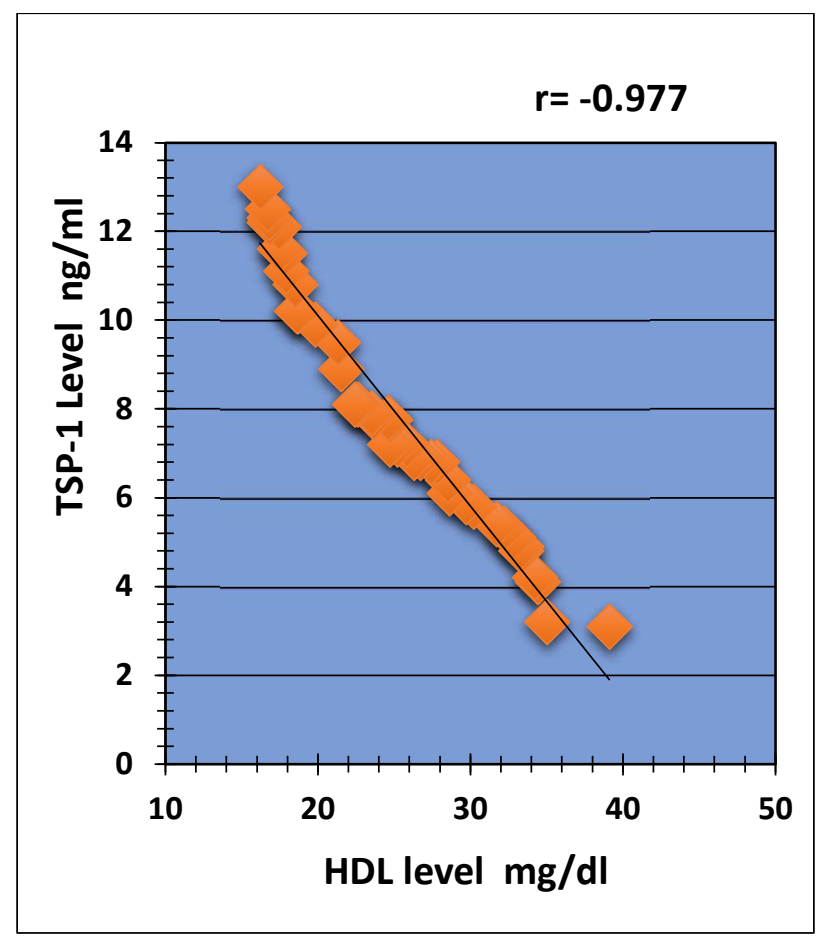

Figure (5): Correlation between TSP-1 and HDL in type 2 DM patients.

\section{DISCUSSION}

The present study revealed a significant increase $(p<0.05)$ in Thrombospondin-1 level and lipid profile levels in diabetic patients in comparing with control groups as presented in table(1). Previous studies suggested that expression of Thrombospondin-1 is markedly up regulated in tissue from diabetic patients and animal models (Kong et al.,2013a;GonzalezQuesada et al.,2013). Other researchers suggests that hyperglycemia potentially induced TSP-1 synthesis by endothelial cells through pathways that may involved glucose mediated activation of hexosamine (Dabir et al., 2008 ;Raman et al.,2011).

Elevated blood glucose concentrations increased TSP-1 synthesis which was associated with reduced cell proliferation, increased TGF- $\beta 1$ bioactivity and stimulation of fibronectin synthesis (Murphy-Ullrich and Poczatek ,2000 and 2008; Yevdokimova et al.,2001) and our previous study indicated a highly relation between TSP-1 and FBG in type 2 diabetic patients (Al-Kraity, W.R.H, 2016). TSP-1 loss also improved metabolic dysfunction, reduced blood glucose (Kong et al.,2013a,b). A multivariate regression analysis study of patients with type 2 diabetic showed that male gender with low level of HDL-C, high level LDL-C and cholesterol are associated with high level of TSP-1 and risk factors of cardiovascular disease (CVD) (Choi et al.,2012). Both male and female diabetic patients with uncontrolled diabetes had severe hyperglycemia and significantly increased triglycerides, cholesterol LDL,VLDL and significantly decreased HDL (Khan,2006;Smith 2007) and these studies were agreement with presented study.

Study of Choi et al.(2012) indicated the association between TSP-1 level and coronary heart disease and atherosclerosis in type 2 diabetic patients. Many studies proved the relation between thrompospondin-1 and LDL-C and these researches indicated that TSP-1 stimulation mediated signaling through a receptor CO-complex involving calreticulin and low density lipoprotein receptors and postulated that transition to inter-mediate adhesive state enhanced cellular responses (Orr et al.,2003a,b). Study of Meng et al.(2010) postulated that LDL-receptor related protein (LRP-1) regulates thrombospondin-1 (TSP-1) enhanced notch signaling and proved a significant relation between LDL-receptor and increment of thrombospondin-1.Previous study indicated that thrombospondin-1 play important 
roles in development of hyperplasia and the relation was suggested between TSP-1 and hypercholesterolemia atherosclerotic rabbits by over express of TSP-1(Roth et al.,1998; Maier et al.,2009).

TSP-1 contributed to development of atherosclerosis and may be important in this complication of diabetes by expressed in the arterial wall and highly correlation was noted between increment of TSP-1 and hypercholesterolemia (Maier et al.,2009).Further studies from laboratory and others have been demonstrated the role of TSP1 in cellular events that contribute to increase cholesterol level and atherosclerosis (Wahab et al .,2005; Ii et al.,2006).

\section{REFERENCES}

Adams, J.C., and Lawler, J. (2004). The thrombospondins. Int. J. Biochem. Cell Biol., 36:961-968.

Alemzadeh, R. ;Wyatt, D.T.; Behrman, R.E.; Kliegman, R.M. and Jenson, H.B. (2008). Diabetes mellitus in children. Nelson Textbook of Pediatrics. $18^{\text {th }}$ ed. Philadelphia: Saunders, 2404-31.

Al-Kraity, W.R.H. and Arshad Noori Ghani AlDujaili, A.N.G, (2016). Assessment of Thrombospondin-1 Level in Type II Diabetic Patients. RJPBCS., 7(6) PP. 1201 -1210.

Bauer, E.M. ; Qin, Y.; Miller, T.W. ; Bandle, R.W. ; Csanyi, G. ; Pagano, P.J. ; Bauer, P.M. ; Schnermann, J. ; Roberts, D.D. ; Isenberg, J.S. (2010).Thrombospondin-1 supports blood pressure by limiting eNOS activation and endothelial-dependent vasorelaxation. Cardiovasc. Res., 88:471-481.

Canadian Diabetes Association (CDA). (2008). Clinical Practice Guideline for the Prevention and Management of Diabetes in Canada. Canadian Journal of Diabetes, 32(1):S1S201.

Canadian Diabetes Association(CDA). (2013). Definition, Classification and Diagnosis of Diabetes: Prediabetes and Metabolic Syndrome. Can. J. Diabetes, 37:S8-S11

Choi, K-Y.; Kim, D-B.; Kim, M-J.; Kown, B-J. ;Chang, S-Y. et al.(2012). Higher Plasma Thrombospondin-1 Levels in Patients With Coronary Artery Disease and Diabetes Mellitus. Korean Circulation Journal, 42:100-106.

\section{CONCLUSION}

The study proved that TSP-1 good marker for monitoring the diabetes mellitus and it's a highly relation between thrombospondin-1 and lipid profile and in type 2 diabetic patients.

\section{ACKNOWLEDGMENT}

My deepest thank to the staff of "Center of Diabetes and Endocrine" in Al-Sadder Teaching Hospital in Najaf city. My deepest thanks and best wishes to the diabetic patients who have agreed to participate in the present study and generously donated the blood and information. I would like to thanks all to all member of Altoosi Unversity Collge, Iraq.

Dabir, P. ; Marinic, T.E. ; Krukovets, I. and Stenina, O.I. (2008). Aryl-hydrocarbon receptor is activated by glucose and regulates the thrombospondin-1 gene promoter in endothelial cells. Circ. Res., 102:65-1558.

Gonzalez-Quesada, C.; Cavalera, M.; Biernacka, A.; Kong, P.; Lee, D.W.; Saxena, A.; Frunza, O.; Dobaczewski, M.; Shinde, A.V. and Frangogiannis, N.G.(2013).Thrombospondin1 Induction in the Diabetic Myocardium Stabilizes the Cardiac Matrix, While Promoting Vascular Rarefaction Through Angiopoietin-2 Upregulation. Circ. Res., 113(12):1331-44.

Ii, M.; Takenaka, H.; Asai, J.; Ibusuki, K.; Mizukami, Y.; Maruyama, K. et al.(2006). Endothelial progenitor thrombospondin-1 mediates diabetes-induced delay in reendothelialization following arterial injury. Circ. Res., 98:697-704.

Jimenez, B.; Volpert, O.V.; Crawford, S.E.; Febbraio, M.; Silverstein, R.L. and Bouck, N. (2000). Signals leading to apoptosisdependent inhibition of neovascularization by thrombospondin-1. Nat. Med., 6: 41-48.

Khan, H.A. (2006). Clinical significance of HbAlc as a marker of circulating lipids in male and female type 2 diabetic patients. Acta. Diabetol.,1-8.

Kong, P.; Gonzalez-Quesada, C.; Li, N.; Cavalera, M.; Lee, D.W. and Frangogiannis, N.G.(2013a). Thrombospondin-1 regulates adiposity and metabolic dysfunction in dietinduced obesity enhancing adipose inflammation and stimulating adipocyte 
proliferation. Am. J. Physiol. Endocrinol. Metab., 305:E439-50.

Kong, P. ; Cavalera, M. and Frangogiannis, N.G.(2013b). The role of thrombospondin-1 (TSP-1) in obesity and diabetes. Adipocyte, $3: 1: 1-4$

Leahy, J. L. and William, T. (2002). insulin Therapy. $1^{\text {st }}$ ed. New York: Marcel Dekker. ISBN.0-8247-0711-7.

Lopez-Dee, Z.; Pidcock, K. and Gutierrez, L.S. (2011). Thrombospondin-1: Multiple paths to inflammation. Mediators Inflamm.,1-10.

Maier, G.M. ; HAN, X. ; Sadowitz, B.; Gentile, K.L.; Middleton, F.A. and Gahton, V. (2009). Thrombospondin-1: A proatherosclerotic protein augmented by hyperglycemia. Journal of Vascular Surgery, 51(5):1238-1247.

Meng, H. ; Zhang, X. ; Lee, S.J. ; Strickland, D.K. ; Lawrence, D.A. and Wan, M.M. (2010). enhancement of Notch3 signaling regulates Thrombospondin-2 (TSP2) LDL-receptor related protein (LRP1). J. Biol. Chem.,1-24.

Murphy, R.; Ellard, S. and Hattersley, A.T.(2008). Clinical implications of a molecular genetic classification of monogenic $\beta$-cell diabetes. Nature Clinical Practice Endocrinology and Metabolism, 4: e200.

Murphy-Ullrich, J.E. and Poczatek, M.(2000). Activation of latent TGF-beta by thrombospondin1: mechanisms and physiology. Cytokine Growth Factor Rev., 11: 59-69.

Orr, A.W.; Pedraza ,C.E.; Pallero, M.A.; Elzie, C.A.; Goicoechea, S.; Strickland, D.K. et al.(2003a). Low density lipoprotein receptorrelated protein is a calreticulin co-receptor that signals focal adhesion disassembly. The Journal of Cell Biology,161:1179-1189.
Orr, A.W. ; Elzie, C.A. ;Kucik, D.F. ;Murph-ullrich, J.E. (2003b). Thrombospondin signaling through the calreticulin/LDL receptor-related protein co-complex stimulates random and directed cell migration. Journal of Cell Science, 116 (14), 2917-2927.

Qian, X. and Tuszynski, G.P.(1996). Expression of thrombospondin-1 in cancer: A role in tumor progression. Proc. Soc. Exp. Biol. Med., 212: 199-207.

Raman, P.; Krukovets, I.; Marinic, T.E.; Bornstein, P. and Stenina, O.I.(2007).Glycosylation mediates up-regulation of a potent antiangiogenic and proatherogenic protein, thrombospondin-1, by glucose in vascular smooth muscle cells. J. Biol. Chem., 282:5704-14.

Roth, J.J.; Gahtan, V.; Brown ,J.L.; Gerhard, C.; Swami, V.K.; Rothman, V.L. et al.(1998). Thrombospondin-1 is elevated with both intimal hyperplasia and hypercholesterolemia. J. Surg. Res., 74:11-6.

Thabrew, I. and Ayling, R.M. (2001). Biochemistry for clinical Medicine. $1^{\text {st }}$ ed. Green wich Medical Media ttd. London. Pp.166-167.

Wahab, N.A.; Schaefer, L.; Weston, B.S. et al.(2005).Glomerular expression of thrombospondin-1, transforming growth factor beta and connective tissue growth factor at different stages of diabetic nephropathy and their interdependent roles in mesangial response to diabetic stimuli. Diabetologia, 48: 2650-2660.

Yevdokimova, N. ; Wahab, N.A. and Mason, R.M.(2001). Thrombospondin-1 is the key activator of TGF-b1 in human mesangial cells exposed to high glucose. J. Am. Soc. Nephrol., 12: 703-712. 